\title{
Obituaries
}

\section{Sir William McCrea 1904 - 1999}

Sir William Hunter McCrea, FRS, or 'Bill' to his friends, was born in Dublin on 13 December 1904, the son of a schoolmaster who moved to England when Bill was two. He was brought up in Derbyshire, attending Chesterfield Grammar School before winning an Entrance Scholarship to Trinity College, Cambridge in 1923, but he always remained proud of his Irish roots and insisted on the Irish spelling of his name.

During his work for the Cambridge Mathematical Tripos, Bill somehow found time also to obtain a first class BSc honours degree in mathematics from London University! In 1926, he began studying for a PhD with R. H. Fowler, whom he greatly respected. In 1927 he was awarded a Rayleigh Prize in Mathematics and was Rouse Ball Senior Student at Trinity, later becoming a Sheepshanks Exhibitioner in Astronomy, and then an Isaac Newton Student. In 1928 he was awarded a Rouse Ball Travelling Studentship which took him to Göttingen for the year 1928-29.

His $\mathrm{PhD}$ thesis was entitled 'Problems concerning the outer layers of the Sun'. At that time, it was still commonly believed that the main constituent of the Sun was iron. In $1928 \mathrm{McCrea}$ followed up a suggestion by Cecilia Payne and by the German astronomer Albrecht Unsöld that in fact hydrogen was dominant. He proved conclusively that this was right in a paper which gave perhaps the first qualitatively correct model of the solar atmosphere, with the currently accepted abundances of about three-quarters hydrogen and one-quarter helium by mass, and led to a series of equally authoritative papers on the atmospheres of other stars.

In common with many astronomers of his generation, most of his academic career was spent in mathematics departments. After two years as a Lecturer in Mathematics in Edinburgh (where he met his future wife, Marian), he quickly moved to a Readership in Mathematics at Imperial College and then in 1936 he moved to his first Chair of Mathematics, at Queen's University, Belfast, back in his native Ireland. After war service with Patrick Blackett's Operational Research Group in the Admiralty, he took over as Professor and Head of the Mathematics Department at Royal Holloway College, where he remained from 1944 to 1966 . Only then did he obtain his first post in astronomy, as founding Research Professor in the Astronomy Centre of the then new University of Sussex. Throughout this time he was always interested in students and found time to talk to them and to answer their questions in a characteristically careful and deliberate manner; at Royal Holloway, he played a prominent part in the staff-student cricket match!

His research spanned many areas of mathematics, physics and astronomy, but he was probably best known for his work on relativity and 
cosmology, a topic which held his interest for more than 60 years. He was an advocate, along with E. A. Milne, of the use of a Newtonian framework to provide simple derivations of the expanding universe models of general relativity, to the benefit of generations of students in cosmology lecture courses! He stressed the importance of developing observable relationships which could be used to constrain cosmological models and the geometry of the universe, and one of his papers from the 1930s was recently republished to make it more accessible to current researchers.

In the 1930s, the bulk of his published papers were on relativistic cosmology or on mathematical topics. However, he did still publish on astrophysics and he was in great demand as an expositor, publishing more than 200 clear and concise abstracts in the Zentralblatt für Mathematik.

In the 1950s, his interest in relativity led to a contentious dispute with Herbert Dingle in the letter pages of Nature on the famous 'twin paradox'. Bill convincingly demonstrated the correctness of this result. At the same period, he was one of the few people to take seriously the steady-state theory developed by Bondi, Gold and Hoyle, and he showed how to treat the theory within the framework of general relativity. He later accepted that the theory was ruled out by observational evidence, but he never completely accepted the alternative big bang model and latterly he became increasingly sceptical about all cosmological models. In his $90 \mathrm{~s}$, he was fond of saying that General Relativity had never been tested in the strong field limit.

In astrophysics, Bill also wrote many influential papers. He always stressed the need for physical understanding and his treatment of the conditions for collapse of a self-gravitating sphere of gas of a uniform temperature is a classic of clarity which has made its way into many lecture courses. He had a particular interest in star formation and developed an innovative model for the origin of the solar system, although it never received much support. He was the first to make a quantitative study of the rate of formation of hydrogen molecules on the surfaces of dust grains in space, a process now recognised as crucial to many reactions in interstellar chemistry. He was quick to realise in the 1960 s that the newly postulated phenomenon of mass transfer in close binaries could be used to explain the presence of the 'blue stragglers' which occupied the extended main sequence of some globular clusters.

Although an eminent scientist, who wrote some 280 scientific papers and six books, Bill also played a major role in national astronomy. From 1944, he spent many years on the Admiralty's Board of Visitors of the Royal Greenwich Observatory (RGO), and on its successor, and wrote a minority report dissenting from the recommendation of the Kingman Report in the 1980s that the RGO should move to Cambridge. His work for the many scientific societies of which he was a member was remarkable in its extent and variety; he held all four offices (President, Secretary, Treasurer and Foreign Correspondent) in the Royal Astronomical Society (RAS) and was on its Council almost continuously from 1936 to 1980 . He was constantly invited to be a visiting professor for long or short periods, acting as an 
unofficial ambassador for British astronomy, and he was the first UK scientist to make an official visit, under the auspices of the Royal Society, to Argentina after the Falklands war. He was particularly pleased to be the first occupant of the Georges Lemaitre chair at the University of Louvain in 1969.

From the 1950s, Bill pressed for the establishment of a national institute for theoretical astronomy. Although this was approved by the Royal Society, the net result instead was the establishment of two institutes, at Cambridge and Sussex. He moved to Sussex in 1966 as founding Research Professor in the Astronomy Centre, with Roger Tayler as a university professor. The proximity of the RGO at Herstmonceux, and the enthusiastic support of RGO staff under Sir Richard Woolley, made for a long and successful partnership between Observatory and University. He succeeded Sir Richard as President of the Sussex Branch of The Mathematical Association. As with all other aspects of his life, he was an extremely conscientious President and took a great interest in the branch, particularly during the Annual Conference at the University of Sussex in 1995. He was national President of The Mathematical Association in 1973-74 and was made an Honorary Member in 1985.

After his retirement in 1972, Bill continued to attend the Astronomy Centre's weekly seminars regularly until the end of 1997, when failing health prevented him from travelling to the university. His deceptively simple but incisive questions were well known to all speakers. Despite increasing blindness, he continued to live alone after his wife died in 1995 and to travel solo to RAS meetings until he was almost 93 . He was a convivial companion on train journeys back to Lewes after eating at the RAS Club.

Throughout his career, Bill accumulated fellowships and honours. He was awarded the Keith Prize of the Royal Society of Edinburgh in 1939-41, the Gold Medal of the RAS in 1976, held five honorary degrees, and was knighted in 1985. Following his election in 1929 he was a Fellow of the RAS for some 70 years, and was also a member or fellow of many other societies, including the London Mathematical Society, The Mathematical Association, the American Astronomical Society, the Royal Society of Edinburgh, the Royal Irish Academy and of course the Royal Society. He was made a Freeman of the City of London in 1988.

Unassuming and modest, Bill had friends and admirers everywhere, and enemies nowhere. His passing marked the end of an era in British astronomy.

ROBERT CONNON SMITH Astronomy Centre, University of Sussex, Falmer, Brighton BNI 9QJ e-mail: R.C.Smith@sussex.ac.uk 